\title{
Diffusible signal factor signaling regulates multiple functions in the opportunistic pathogen Stenotrophomonas maltophilia
}

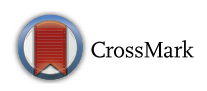

Shi-qi $\mathrm{An}^{1 *}$ and Ji-liang Tang ${ }^{2^{*}}$

\begin{abstract}
Objective: Stenotrophomonas maltophilia is a Gram-negative bacterium commonly isolated from nosocomial infections. Analysis of the genome of the clinical S. maltophilia isolate K279a indicates that it encodes a diffusible signal factor (DSF)-dependent cell-cell signaling mechanism that is highly similar to the system previously described in phytopathogens from the genera Xanthomonas and Xylella. Our objective was to study the function of DSF signaling in the clinical strain S. maltophilia K279a using genetic and functional genomic analyses.
\end{abstract}

Results: We compared the wild-type strain with a mutant deficient in the rpfF (regulation of pathogenicity factors) gene that is essential for the synthesis of DSF. The effects of disruption of DSF signaling were pleiotropic with an impact on virulence, biofilm formation and pathogenesis. The phenotypic effects of rpfF mutation in S. maltophilia could be reversed by addition of exogenous DSF. Taken together, we demonstrate that DSF signaling regulates factors contributing to virulence, biofilm formation and motility of this important opportunistic pathogen.

Keywords: Stenotrophomonas maltophilia, Cell-cell signaling, Diffusible signal factor, Antibiotic resistance, Biofilm formation, Virulence

\section{Introduction}

Stenotrophomonas maltophilia is a Gram-negative bacterium that is found ubiquitously in the environment and which has become an important opportunistic pathogen [1-3]. S. maltophilia infections occur in cystic fibrosis and burns patients and are common in individuals with compromised immune systems who are inclined to opportunistic infections [1-3]. The organism is commonly isolated from clinical specimens and is involved in urinary and respiratory tract infections, endocarditis and in catheter-related bacteraemia and septicaemia [1-3]. Isolates are resistant to the majority of clinically useful antibiotics making the treatment of S. maltophilia infections problematic [4]. A number of laboratories have

\footnotetext{
*Correspondence: s.an@qub.ac.uk; jtang@gxu.edu.cn

${ }^{1}$ Wellcome Wolfson Institute for Experimental Medicine, Queen's

University Belfast, 97 Lisburn Road, Belfast BT9 7BL, UK

${ }^{2}$ College of Life Science and Technology, State Key Laboratory

for Conservation and Utilization of Subtropical Agro-bioresources,

Guangxi University, 100 Daxue Road, Nanning 530004, Guangxi, China
}

been addressing the molecular bases for virulence and antibiotic resistance in S. maltophilia [1-3, 5, 6].

Stenotrophomonas maltophilia is related to bacteria from the genera Xanthomonas and Xylella [7]. In Xanthomonads, cell-cell signaling mediated by molecules of the diffusible signal factor (DSF) family control virulence factor synthesis, development of biofilms as well as disease in plants (reviewed in Ryan et al. [8]). Furthermore, these signal molecules have been shown to play a role in Xylella interaction with its insect vector (reviewed in Ryan et al. [8]). DSF family signal molecules are cisunsaturated fatty acids, the first of which to be identified was cis-11-methyl-2-dodecenoic acid from Xanthomonas campestris [9]. The synthesis and perception of the signals require products of the $r p f$ gene cluster; DSF synthesis is dependent on RpfF, which has some amino acid sequence similarity to enoyl-CoA hydratases, whereas DSF perception involves a two-component regulatory system, including the complex sensor RpfC and response regulator RpfG [8-11]. In $X$. campestris, the rpfG and $r p f C$ genes are co-transcribed as the $r p f G H C$ operon, 
although RpfH has no clear role in signaling and is not conserved in other Xanthomonas species or in Xylella [12]. The $r p f B$ gene, which encodes a long-chain fatty acyl coenzyme A ligase, is linked to rpfF in X. campestris and has been implicated in DSF turnover [13]. The relatedness of S. maltophilia to these plant pathogens prompted us to examine this organism for the existence and role of a DSF-dependent signaling system. In 2007, it was reported that mutation of rpfF had effects on different phenotypes in S. maltophilia [14]. However, this paper was recently retracted due to errors in data presentation [15]. Here we report on the outcomes of repeated key experiments that indicate the pleiotropic nature of rpfF mutation and show that DSF signaling controls factors contributing to virulence, motility and biofilm formation of this nosocomial pathogen.

\section{Main text}

\section{Methodology}

\section{Bacterial strains and growth conditions}

For the majority of experiments, NYGB medium was used as growth media for S. maltophilia strains, which contains $20 \mathrm{~g} / \mathrm{L}$ glycerol (Sigma-Aldrich, UK), $3 \mathrm{~g} / \mathrm{L}$ yeast extract (Difco, UK) and $5 \mathrm{~g} / \mathrm{L}$ bacteriological peptone (Oxoid, UK). The measurement bacterial biofilm formation was carried out in L medium, which comprises of sodium chloride, $5 \mathrm{~g} / \mathrm{L}$; yeast extract, $5 \mathrm{~g} / \mathrm{L}$; Bactotryptone (Difco, UK), $10 \mathrm{~g} / \mathrm{L}$ and D-glucose (Sigma-Aldrich, $\mathrm{UK}), 1 \mathrm{~g} / \mathrm{L}$.

The strain of S. maltophilia used was K279a [4]. In this study in order to create a disruption of the $r p f F$ gene in $S$. maltophilia, an internal fragment of the gene was amplified using the primers PEX18RPFF-F: $5^{\prime}$-TGACATCGT CGACGACTACCAGC-3') and PEX18RPFF-R: $5^{\prime}$-GGC TTTCCTTGATCACCTGT- $3^{\prime}$ and was cloned into the TOPO (Invitrogen) vector. This fragment was excised with EcoRI and ligated into the suicide plasmid pEX18Tc [16]. This construct was introduced into S. maltophilia K279a by triparental mating. The mating mixture was plated on NYGA medium containing tetracycline $(125 \mu \mathrm{g} / \mathrm{mL})$ to select for mutants. S. maltophilia K279a has low intrinsic level of tetracycline tolerance. Candidate strains were analyzed by colony PCR using the primers Con-F: $5^{\prime}$-TTG CGTATTGGGCGCTCTTCC-3' ${ }^{\prime}$ and Con-R: $5^{\prime}$-ACG ATGATCGGCCTGTCGCT- $3^{\prime}$ to confirm disruption of the $r p f F$ gene by the suicide vector. For complementation studies, the $r p f F$ gene was cloned into pBBR1MCS [17].

For the complementation of $X$. campestris strains, the rpfF gene from S. maltophilia K279a with its promoter was amplified by PCR using the primers RPFFCOMF: $5^{\prime}$-GAATTCAGACGGCGGGGTCTTT- $3^{\prime}$ and RPFFCOMR: $\quad 5^{\prime}$-AAGCTTTCAGGCCGGGTCGCCATT- ${ }^{\prime}$ and the DNA fragment cloned into the TOPO vector.
The rpfF gene was excised as a EcoRI-HindIII fragment and ligated into pLAFR3 [10] cut with the same enzymes. This resulting construct was introduced into selected $X$. campestris strains by triparental mating.

\section{DSF extraction and synthetic DSF}

DSF was extracted into ethyl acetate from culture supernatants of strains grown in NYGB as described by Barber and colleagues [10]. DSF was assayed by measuring the restoration of endoglucanase activity to an X. campestris rpfF mutant strain 8523 by extracts from culture supernatants [10]. Synthetic DSF from X. campestris (cis-11-Methyl-2-dodecenoic acid) was purchased from Merck (Sigma-Aldrich, UK).

\section{Extracellular enzymes assays}

For measurement of protease activity, strains were grown in NYG medium, $3 \mu \mathrm{L}$ of the overnight cultures $\mathrm{OD}_{600}$ $\mathrm{nm} \approx 1.0$ ) were spotted onto an NYG plate containing $1 \%$ $(\mathrm{w} / \mathrm{v})$ skimmed milk and allowed to dry before growth at $30{ }^{\circ} \mathrm{C}$ for 24(h). For measurement of endoglucanase activity, strains were grown in NYG medium overnight. Enzyme activity in cell-free culture supernatants were measured by radial diffusion assays into substrate-containing agar plates using carboxymethyl cellulose (CMC) as substrate [10].

\section{Motility assays}

Bacterial motility assays were carried out on NYGB media that was solidified using $0.6 \%$ Eiken agar (Eiken Chemical, Tokyo). A sterile 200- $\mu \mathrm{L}$ tip was used to inoculate $S$. maltophilia strains to the centre of the plate. Plates were visualized after incubated at $30^{\circ} \mathrm{C}$ for $48 \mathrm{~h}$.

\section{Biofilm formation assay}

Bacterial strains were assessed for biofilm formation by aggregation in L medium as described previously [18]. Here log-phase-grown bacteria were diluted to $\mathrm{OD}_{600}$ $\mathrm{nm}=0.02$ in $\mathrm{L}$ media broth, and $5 \mathrm{~mL}$ was incubated at $30{ }^{\circ} \mathrm{C}$ for $24 \mathrm{~h}$ in $14 \mathrm{~mL}$ glass tubes.

\section{Virulence assay}

Virulence was tested in Galleria mellonella larvae [19], which were stored at $4{ }^{\circ} \mathrm{C}$ in wood shavings. G. mellonella were injected with $10 \mu \mathrm{L}$ of successively diluted bacteria $\left(1 \times 10^{6} \mathrm{CFU}\right)$. Infected G. mellonella were placed on Whatman paper lined Petri dishes and incubated at $37{ }^{\circ} \mathrm{C}$. The G. mellonella were monitored for their survival after a $24 \mathrm{~h}$ period. Four separate tests were conducted consisting of 10 larvae for each strain. The control groups for each experiment consisted of G. mellonella injected with PBS alone. 


\section{Results and discussion}

Initial evidence for the occurrence of the DSF signaling system in S. maltophilia clinical isolate K279a was provided by bioinformatic analysis. Interrogation of the genome sequence of this organism (http://www. sanger.ac.uk/Projects/S_maltophilia/) using with the RpfF amino acid sequence of $X$. campestris in tBLASTn revealed a homolog of RpfF. Further analysis of a DNA sequence of approximately $8 \mathrm{~Kb}$ (to include flanking genes) indicated the presence of an rpfBFCG gene cluster, related to that found in $X$. campestris (Fig. 1). No homologue of rpfH was identified in S. maltophilia (Fig. 1). The $S$. maltophilia proteins showed very high amino acid sequence similarity to their homologues in $X$. campestris; in BLASTP comparisons, E values were lower than $10^{-127}$.

These bioinformatic studies were supported by experimental studies to examine the production of DSF by the K279a strain. DSF in extracts of culture supernatants was assayed by measuring the restoration of endoglucanase activity to an $X$. campestris rpfF mutant (see "Methodology"). Using this bioassay, DSF activity was detected in culture supernatants of S. maltophilia K279a (Fig. 1). Further evidence that the product of the S. maltophilia K279a rpfF gene directs DSF production was obtained from experiments in which the cloned gene was introduced into the rpfF mutant of $X$. campestris. The transconjugant produced detectable DSF production and the production of the extracellular enzymes endoglucanase and protease was concomitantly restored (Fig. 1). Furthermore, inactivation of rpfF in S. maltophilia K279a by use of the pEX18Tc suicide vector (see "Methodology") led to a loss of DSF synthesis as (Fig. 1).

The effects of disruption of DSF signaling through inactivation of rpfF in S. maltophilia K279a were pleiotropic. The $r p f F$ mutant had severely reduced motility (Fig. 2), decreased levels of extracellular protease (Fig. 2) and formed aggregates or biofilms when grown in $\mathrm{L}$ medium (Fig. 2). Importantly, in trans expression

a Xanthomonas campestris pv. campestris

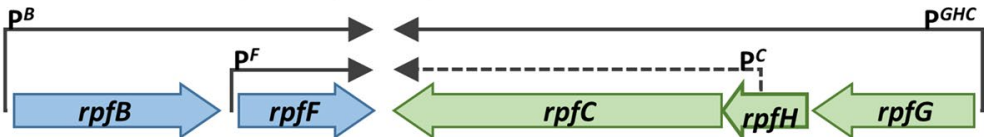

b(ii)

Stenotropphomonas maltophilia
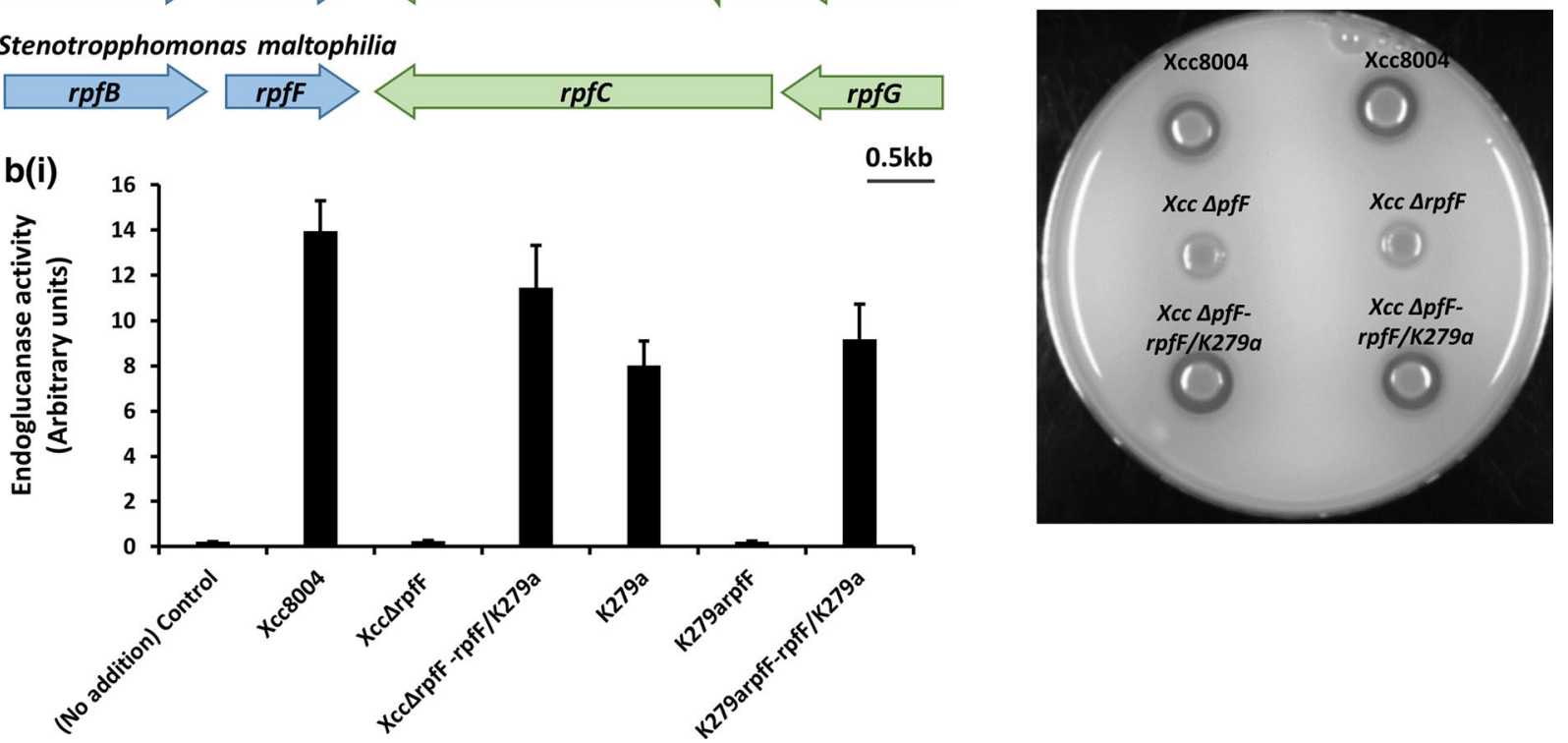

Fig. 1 a Physical map of the part of the rpf gene cluster from rpfB to rpfG in Xanthomonas campestris and Stenotrophomonas maltophilia K279a. The organization of ORFs predicted by sequence analysis together with predicted directions of transcription are indicated by the broad arrows. The positions of the experimentally determined transcriptional start sites in X. campestris together with the predicted transcripts are shown as single arrows. The sequence data for S. maltophilia were produced by the S. maltophilia K279a Sequencing Group at the Sanger Institute and can be obtained from http://www.sanger.ac.uk/Projects/S_maltophilia/). $\mathbf{b}$ DSF activity in culture supernatants of strains of S. maltophilia K279a and X. campestris. Extracts were assayed using a Xanthomonas bioassay in which restoration of endoglucanase activity to an rpfF mutant is measured (i). Introduction of the rpfF gene from S. maltophilia K279a restores the synthesis of protease to the rpfF mutant of X. campestris (ii). Enzyme activity was assessed by zones of clearing produced after growth of bacteria on skimmed milk agar plates. Top panel: Protease production in $X$. campestris wild-type (Xcc 8004). Middle panel: Protease production in X. campestris rpfF mutant (Xcc $\Delta p f F)$. Right panel: Protease production by Xcc $\Delta p f F$ carrying the S. maltophilia rpfF gene cloned in pLAFR3 

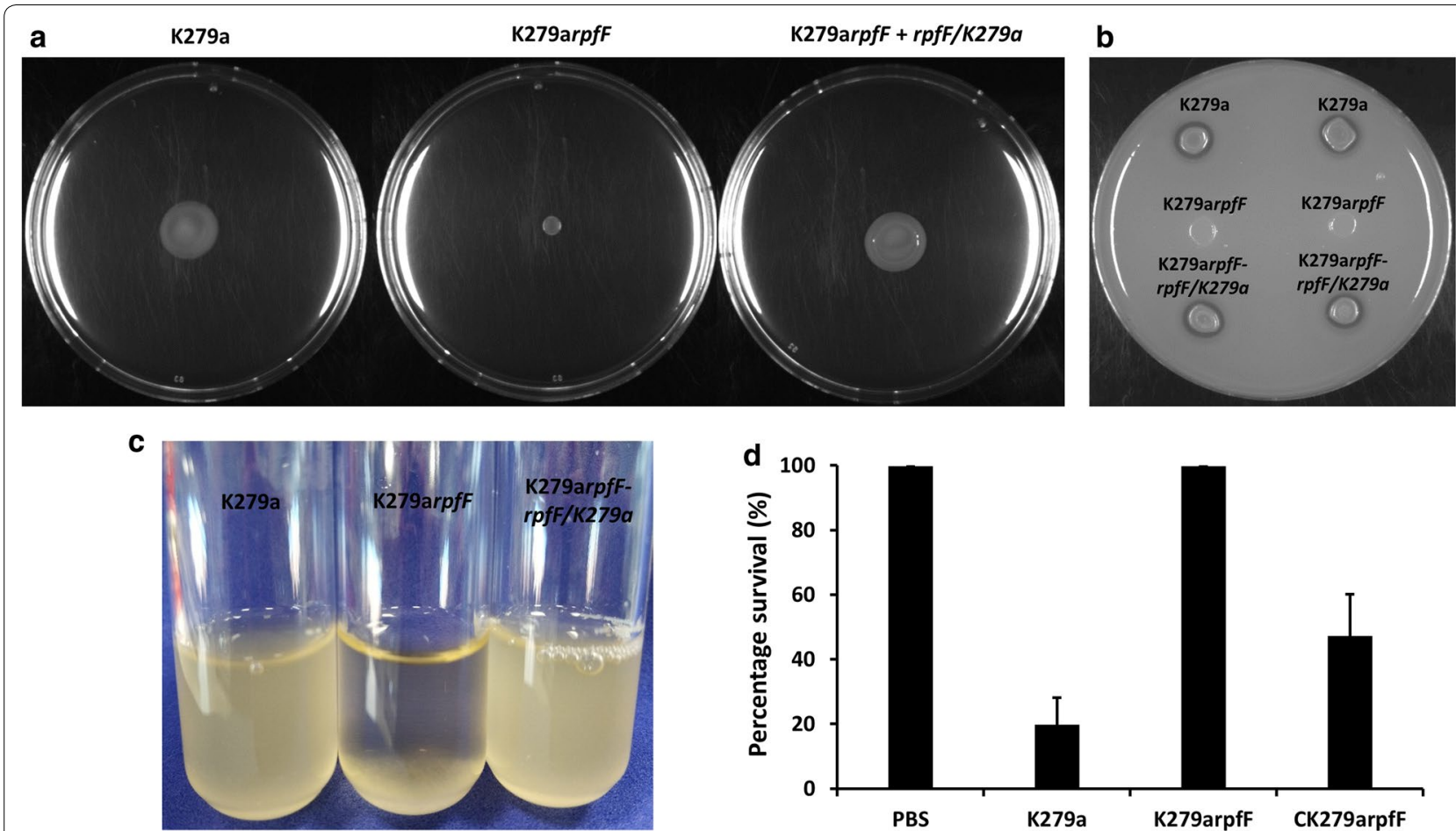

Fig. 2 Loss of DSF signaling through mutation of rpfF has a pleiotropic effect in S. maltophilia. The rpfF mutant shows reduced motility in 0.6\% Eiken agar (a); reduced production of extracellular protease $(\mathbf{b})$; aggregation when grown in $L$ medium (c), where the wild-type grows in a dispersed fashion; d ability to cause disease to Galleria mellonella (Wax moth larvae). In trans expression rpff gene in the S. maltophilia rpff mutant could restore phenotypes towards wild-type in all cases

of the $r p f F$ gene in the mutant could restore phenotypes towards wild-type in all cases.

The above findings demonstrated the impact of DSF signaling on aggregative behavior and protease synthesis in S. maltophilia, which are functions that are believed to be involved in virulence. This motivated us to test the effect of rpfF mutation on S. maltophilia virulence using the Galleria mellonella larvae model (see "Methodology"). Under the assay conditions used, the wild-type $S$. maltophilia K279a killed the majority of larvae after $24 \mathrm{~h}$, whereas the rpfF mutant of S. maltophilia K279a produced no killing (Fig. 2). These findings suggest that DSF signaling contributes to the virulence of $S$. maltophilia. The pleiotropic effects of loss by mutation rpfF are consistent with previous observations in different strains of S. maltophilia and species of Stenotrophomonas such as S. rhizophila, where rpfF mutants have altered biofilm formation, extracellular polysaccharide synthesis and virulence $[5,6]$.

The phenotypic effects of rpfF mutation in S. maltophilia could be reversed by addition of exogenous DSF. Addition of synthetic DSF from $X$. campestris at $1 \mathrm{mM}$ or extracts from wild-type $S$. maltophilia to cultures of the $S$. maltophilia rpfF mutant of an equivalent volume restored wild-type planktonic growth in L medium and restored motility towards wild-type levels (Fig. 3). The work is consistent with recent studies that identify the importance of RpfF proteins and DSF signaling in regulation in other environmental strains of S. maltophilia [5, 6].

\section{Conclusions}

The work in this paper suggests that DSF signaling in $S$. maltophilia has a role in the regulation of a number of functions that contribute to aggregation or biofilm formation and to the virulence of this organism. Our findings thus add to a body of work that indicates a role for cell-cell signaling in the virulence of diverse bacterial pathogens. Interference with such signaling processes affords a rational approach to aid the treatment of bacterial infections. However, one limitation of such an approach is that differences in the operation of Rpf-DSF mediated cell-cell signaling have been reported in different strains of S. maltophilia to include both clinical and environmental isolates. In this context, a detailed study of DSF signaling and its role in a wider number of $S$. maltophilia isolates is very much warranted. 


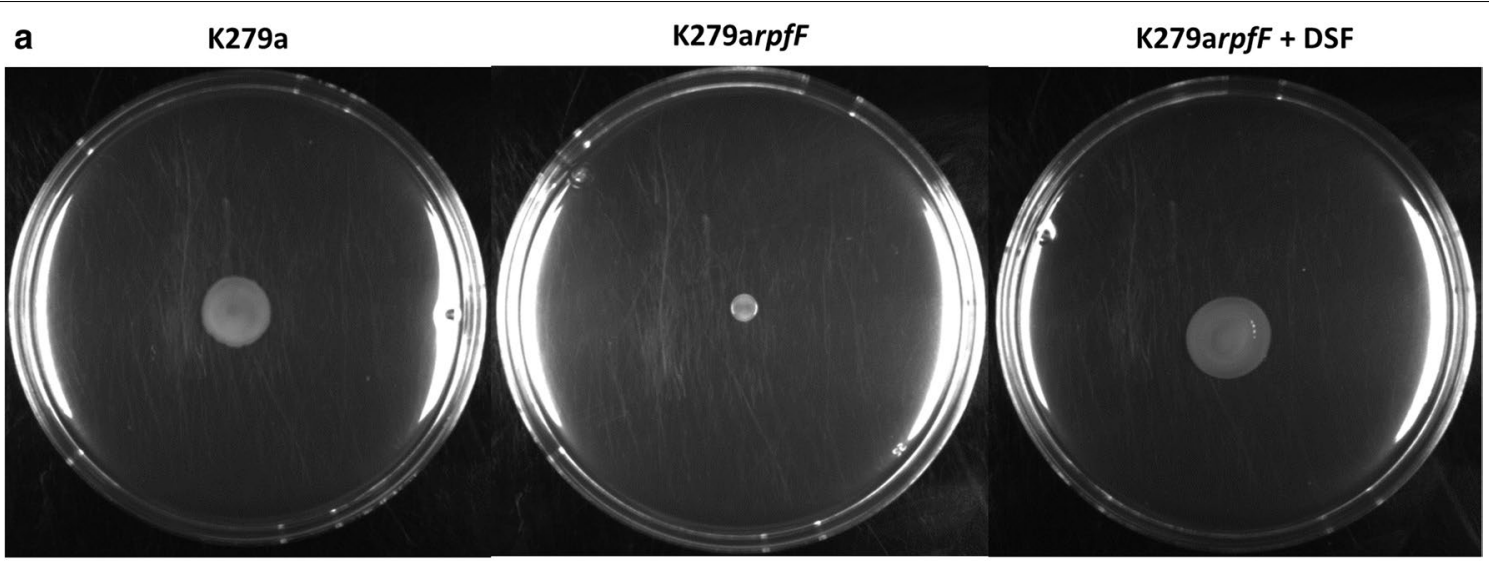

b

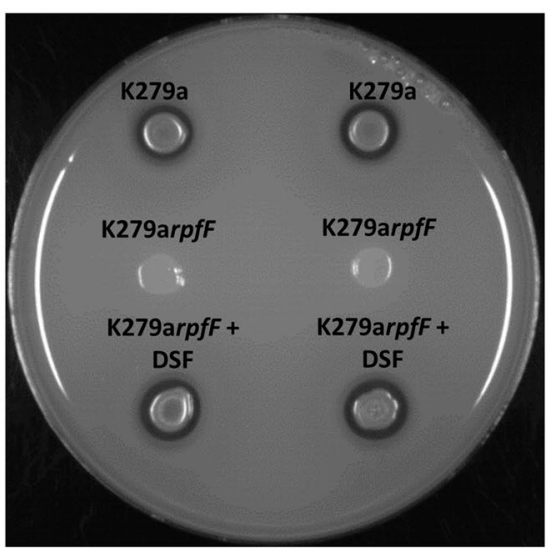

C

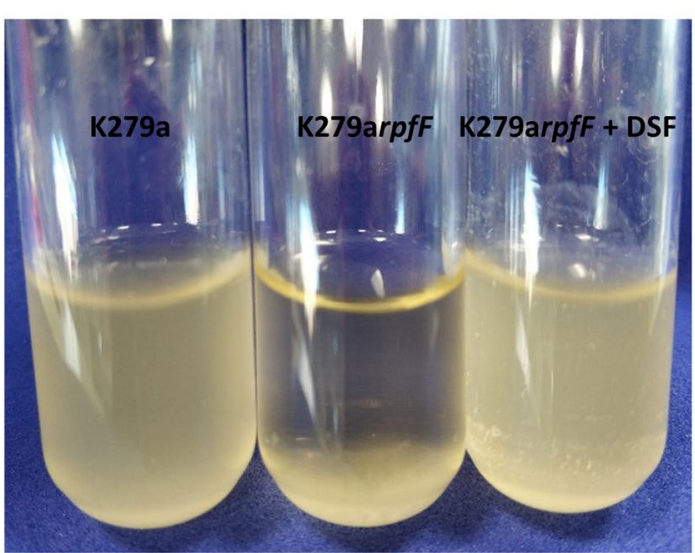

Fig. 3 Addition of DSF to agar plates restores motility to the S. maltophilia rpfF mutant. The addition of DSF to agar plates restores $\mathbf{a}$ motility; $\mathbf{b}$ production of extracellular protease; $\mathbf{c}$ wild-type planktonic growth in $\mathrm{L}$ medium to the $S$. maltophilia rpfF mutant

\section{Limitations}

- The study focuses on a single sequenced strain of $S$. maltophilia.

- The molecular mechanism for how the DSF signal is perceived by $S$. maltophilia and regulates the specific phenotypes observed is not investigated.

\section{Abbreviations}

DSF: diffusible signal factor; Rpf: regulation of pathogenicity factors; OD: optical density; Xcc: Xanthomonas campestris pv. campestris.

\section{Authors' contributions}

Experimental design: SQA; JLT. Experimental work: SQA; JLT. Data analysis:

SQA, JLT. Writing manuscript: SQA, JLT. Reviewing manuscript: all authors. Both authors read and approved the final manuscript.

\section{Acknowledgements}

We thank Robert Ryan, Max Dow and Delphine Caly for initial data, helpful discussions and critical reading of the manuscript.

\section{Competing interests}

The authors declare that they have no competing interests.

\section{Availability of data and materials}

All data generated or analysed during this study are included in this published article.

\section{Consent for publication}

Not applicable.

\section{Ethics approval and consent to participate}

Not applicable.

\section{Funding}

This work was supported in part by funding from the Ba Gui Scholar Program of Guangxi Zhuang Autonomous Region of China 2014A002 to JLT.

\section{Publisher's Note}

Springer Nature remains neutral with regard to jurisdictional claims in published maps and institutional affiliations.

Received: 9 July 2018 Accepted: 6 August 2018

Published online: 10 August 2018 


\section{References}

1. Ryan RP, Monchy S, Cardinale M, Taghavi S, Crossman L, Avison MB, et al. The versatility and adaptation of bacteria from the genus Stenotrophomonas. Nat Rev Microbiol. 2009;7:514-25.

2. Berg G, Martinez JL. Friends or foes: can we make a distinction between beneficial and harmful strains of the Stenotrophomonas maltophilia complex? Front Microbiol. 2015:6:241.

3. An S, Berg G. Stenotrophomonas maltophilia. Trends Microbiol. 2018:26(7):637-8.

4. Crossman LC, Gould VC, Dow JM, Vernikos GS, Okazaki A, Sebaihia M, et al. The complete genome, comparative and functional analysis of Stenotrophomonas maltophilia reveals an organism heavily shielded by drug resistance determinants. Genome Biol. 2008;9(4):R74.

5. Alavi P, Müller H, Cardinale M, Zachow C, Sánchez MB, Martínez JL, et al. The DSF quorum sensing system controls the positive influence of Stenotrophomonas maltophilia on plants. PLoS ONE. 2013;8(7):e67103.

6. Huedo P, Yero D, Martinez-Servat S, Ruyra À, Roher N, Daura X, et al. Decoding the genetic and functional diversity of the DSF quorum-sensing system in Stenotrophomonas maltophilia. Front Microbiol. 2015;6:761.

7. Minkwitz A, Berg G. Comparison of antifungal activities and 165 ribosomal DNA sequences of clinical and environmental isolates of Stenotrophomonas maltophilia. J Clin Microbiol. 2001;39(1):139-45.

8. Ryan RP, An SQ, Allan JH, McCarthy Y, Dow JM. The DSF family of cell-cell signals: an expanding class of bacterial virulence regulators. PLoS Pathog. 2015;11(7):e1004986.

9. Wang LH, He Y, Gao Y, Wu JE, Dong YH, He C, et al. A bacterial cell-cell communication signal with cross-kingdom structural analogues. Mol Microbiol. 2004;51(3):903-12.

10. Barber CE, Tang JL, Feng JX, Pan MQ, Wilson TJG, Slater $H$, et al. A nove regulatory system required for pathogenicity of Xanthomonas campestris is mediated by a small diffusible signal molecule. Mol Microbiol. 1997;24(3):555-66.

11. An S-Q, Febrer M, McCarthy Y, Tang D-J, Clissold L, Kaithakottil G, et al. High-resolution transcriptional analysis of the regulatory influence of cell-to-cell signalling reveals novel genes that contribute to Xanthomonas phytopathogenesis. Mol Microbiol. 2013;88(6):1058-69.

12. Newman KL, Almeida RPP, Purcell AH, Lindow SE. Cell-cell signaling controls Xylella fastidiosa interactions with both insects and plants. Proc Natl Acad Sci. 2004;101(6):1737-42

13. Zhou $L$, Wang $X-Y$, Sun $S$, Yang $L-C$, Jiang B-L, He Y-W. Identification and characterization of naturally occurring DSF-family quorum sensing signal turnover system in the phytopathogen Xanthomonas. Environ Microbiol. 2015:17(11):4646-58.

14. Fouhy Y, Scanlon K, Schouest K, Spillane C, Crossman L, Avison MB, et al. Diffusible signal factor-dependent cell-cell signaling and virulence in the nosocomial pathogen Stenotrophomonas maltophilia. J Bacteriol. 2007;189(13):4964-8

15. Fouhy Y, Scanlon K, Schouest K, Spillane C, Crossman L, Avison MB, et al. Retraction for Fouhy et al., Diffusible signal factor-dependent cell-cell signaling and virulence in the nosocomial pathogen Stenotrophomonas maltophilia. J Bacteriol Am Soc Microbiol. 2018;200(12):e00235-18.

16. Hoang TT, Karkhoff-Schweizer RR, Kutchma AJ, Schweizer HP. A broadhost-range F1p-FRT recombination system for site-specific excision of chromosomally-located DNA sequences: application for isolation of unmarked Pseudomonas aeruginosa mutants. Gene. 1998;212(1):77-86.

17. Kovach ME, Elzer PH, Steven Hill D, Robertson GT, Farris MA, Roop RM, et al. Four new derivatives of the broad-host-range cloning vector pBBR1MCS, carrying different antibiotic-resistance cassettes. Gene. 1995;166(1):175-6.

18. Dow JM, Crossman L, Findlay K, He Y-Q, Feng J-X, Tang J-L. Biofilm dispersal in Xanthomonas campestris is controlled by cell-cell signaling and is required for full virulence to plants. Proc Natl Acad Sci. 2003;100(19):10995-1000.

19. An S, Tang J. The Ax21 protein influences virulence and biofilm formation in Stenotrophomonas maltophilia. Arch Microbiol. 2018;200(1):183-7.
Ready to submit your research? Choose BMC and benefit from:

- fast, convenient online submission

- thorough peer review by experienced researchers in your field

- rapid publication on acceptance

- support for research data, including large and complex data types

- gold Open Access which fosters wider collaboration and increased citations

- maximum visibility for your research: over $100 \mathrm{M}$ website views per year

At $\mathrm{BMC}$, research is always in progress.

Learn more biomedcentral.com/submissions 